\title{
NARRATIVAS DE ESTUDANTES DE PEDAGOGIA SOBRE TEMAS NECESSÁRIOS À EDUCAÇÃO EM DIREITOS HUMANOS (EDH)
}

ETHNOGRAPHICAL OF PEDAGOGYSTUDENTS ON TOPICSIN HUMAN RIGHTS EDUCATION (HRE)

\section{NARRATIVAS DEESTUDIANTES DE PEDAGOGÍA SOBRE TEMAS NECESARIOS PARA LAEDUCACIÓNEN DERECHOS HUMANOS (EDH)}

\author{
Fernando Guimarães Oliveira da Silva \\ Programa de Pós-graduação em Educação da \\ Universidade Estadual de Mato Grosso do Sul \\ (UEMS) \\ E-mail: fernando.oliveira@uems.br

\section{Eliane Rose Maio} \\ Programa de Pós-graduação em Educação da \\ Universidade Estadual de Maringá (UEM) \\ E-mail: elianerosemaio@yahoo.com.br
}

\section{INTRODUÇÃO}

Estudos recentes na área da educação têm ressaltado a relevância da Pes-

Equisa na formação do/da futuro/a professor/a. É o que trata Marli André (2010) ao apontar que o envolvimento com atividades, cursos, e experiências de professores/as atuantes representa parte do processo de constituição da identidade profissional docente. Ora, assim como André (2010), acreditamos ser necessário que, no processo de formação inicial, os/as alunos/as participem de espaços, no que se refere à dimensão do ensino, para que a pesquisa seja elemento mediador de novas aprendizagens.

André (2010), em seu trabalho, se debruça sobre o resultado da análise de dez eventos no campo da didática e das práticas de ensino, os Encontros 
Nacionais de Didática e Práticas de Ensino (ENDIPE). Segundo a autora, o tema da formação inicial vem progressivamente perdendo espaço para outras discussões no ambiente educacional: "Esse fato causa muita preocupação porque ainda há muito a conhecer sobre como preparar os docentes para enfrentar os desafios da educação no século XXI" (ANDRÉ, 2010, p. 177). O processo de formação docente, conclui, precisa estar vinculado ao real e possível das escolas.

Diferente do passado, que distanciava teoria e prática, a formação inicial, hoje, necessita de investimento teórico-prático para fortalecer uma identidade profissional comprometida com transformações societárias mais amplas e atuais, pertinentes ao tempo presente. Vale destacar, nesse sentido, que a nossa compreensão dos aspectos societários que influenciam o processo educacional se pauta nos estudos de Zigmunt Bauman e David Lyon (2013).

No entendimento dos sociólogos (BAUMAN; LYON, 2013), vivemos em uma sociedade na qual o investimento no consumo é decisivo para a satisfação dos desejos, necessidades e vontades, desde que sirva para certo "valor social" e à autoestima do indivíduo: "Por essa razão, em última instância, passar no teste de consumidor é condição inegociável para a admissão numa sociedade que foi remodelada à feição do mercado" (BAUMAN; LYON, 2013, p. 38). Observam-se, de fato, no ambiente escolar, variadas situações, materiais e simbólicas, em que há a presença do consumo de informações. Isso porque os/as próprios/as membros dessa sociedade são as mercadorias de consumo de grandes redes produtoras de sentidos sobre a vida, a existência, o próprio consumo etc.

Logo, muitas preocupações acabam por permear os estudos sobre a Educação em Direitos Humanos (EDH). Não foi tarefa fácil para o primeiro autor deste artigo, enquanto docente no Ensino Superior, associar as duas questões, a formação inicial docente e a EDH, sem que a queda no fosso dos preconceitos fosse certeira. Ranços históricos, como a essência e a noção de natureza humana, ainda estão presentes. Porém, quando em disputa por uma ação pedagógica menos tolhida e mais aberta à experimentação de possibilidades, é preciso continuar a mediar discussões que tenham o público como alvo.

A ideia de conduzir uma ação docente com enfoque no público faz com que a percepção a respeito da diversidade humana seja um elemento 
norteador do processo. Ainda assim, é possível notar que muitas estudantes, antes de ingressarem no campo científico da educação, produzem uma cultura configurada pela defesa de uma certa sociedade, e isso pode refletir na concepção que elas têm a respeito da EDH.

Ao dissertarem sobre a Educação em Direitos Humanos e a formação de professores/as, Vera Candau e Suzana Sacavino (2013) assumem uma perspectiva histórico-crítica dos direitos humanos e articulam direitos da igualdade e direitos da diferença. As autoras indicam que a prática dos/as professores/ as, quando abordam o assunto, limita-se a transmitir direitos da atualidade, apagando problematizações históricas mais amplas.

Isso significa que é preciso formar o/a futuro/a professor/a para lidar com o público, o diferente, e não para empregar visões egoísticas da vida, que desprezam a diversidade. Esse foi o plano que orientou o objetivo geral da disciplina Educação, democracia e direitos humanos aplicada à uma turma de sete alunas do curso de Pedagogia de uma Instituição de Ensino Superior Privada (IES) do leste sul-mato-grossense durante o primeiro semestre de 2019.

Aliada à proposta de integrar aspectos da democracia e dos direitos humanos, a organização do trabalho didático ${ }^{1}$ previu a adoção de estratégias para promover o acesso à leitura de conceitos sobre os dois assuntos e também problematizar o imaginário social a respeito de diferentes sujeitos nessa conjuntura (negros, índios, pessoas com deficiências, mulheres, lésbicas, gays, pessoas trans etc.) suas disputas, privilégios e desafios, para, assim, compreender as demandas presentes na EDH.

A pesquisa sobre a localização da EDH no imaginário dessas estudantes² só foi possível, contudo, graças ao fato de que ela estava vinculada ao Estágio obrigatório nas séries iniciais do Ensino Fundamental requerido pela IES.

Definido com as alunas o papel da pesquisa no processo de formação docente, prosseguimos com a elaboração do instrumental que roteirizava as

\footnotetext{
1 Sobre a organização do trabalho didático, ler Gilberto Alves (2012).

${ }^{2}$ A partir de orientações de Jeferson Mainardes e Isabel Carvalho (2019), em publicação junto à Associação Nacional de Pesquisa e Pós-graduação em Educação intitulada Ética e Pesquisa em Educação: subsídios, a autodeclaração de princípios e procedimentos éticos na pesquisa em educação é fundamental nos casos em que o projeto não foi submetido a Comitês ou Comissões de ética na pesquisa. É o caso desse estudo, onde realizou-se um documento assinado pelas estudantes para autorizar a publicação de suas experiências.
} 
situações do cotidiano escolar que poderiam, na perspectiva da interdisciplinaridade, e diante do currículo proposto, ser assunto em sala de aula.

Elaborado e analisado o roteiro, tornou-se indispensável tratar de modo ético a pesquisa. Para tanto, foram descritos, a princípio, os aspectos relevantes da participação das estudantes (futuras professoras) no estudo, além dos propósitos da investigação. Indicamos as características da formação inicial, o assunto a ser abordado e a possibilidade de contribuição por parte da estudante. Foi explicitada a não obrigatoriedade da participação, bem como da divulgação das experiências particulares. Todas as estudantes, no entanto, desejaram contribuir com a pesquisa, solicitando, somente, que os seus nomes não fossem divulgados. Ciente dessa rogativa, aplicamos o questionário e trouxemos as questões para discussão em sala de aula.

Nesse momento, tratamos não apenas de ofertar às estudantes a compreensão de que diferentes formas de violências, preconceitos e segregação coexistem porque acontece, há muito, um silenciamento de suas discussões no ambiente escolar; procuramos promover ao sujeito-docente iniciante, sobretudo, a oportunidade de abordar um tema que pouco se pensa associado à unidade escolar. O objetivo, deste modo, foi o de se valer de situações relacionadas à potencialização do ódio contra as diferenças, as assimetrias e desigualdades que refletiram sobre as relações infantis durante o estágio curricular obrigatório, para que a ação docente, por meio de práticas de ensino com o enfoque na $\mathrm{EDH}$, pudesse, no futuro, se preocupar com tais dimensões. Em outras palavras, procuramos permitir às estudantes um olhar para si mesmas em diálogo com a ordem moral que as criou, e independente das pressões que julgam experiências libertárias do existir, a fim de que elas se vissem mais afeitas às diferenças e conseguissem estabelecer novas relações com o novo.

A pesquisa, enfim, foi abordada sob a perspectiva das teorias pós-críticas em educação. Dagmar Meyer e Marlucy Paraíso (2014, p. 22-23) acreditam que esse recorte permite apreender "um tempo que demanda de nós não apenas a compreensão do mundo em que vivemos, mas, sobretudo, a criação de instantes de suspensão dos sentidos já criados e a abertura de possibilidades de sua ressignificação". Segundo as autoras, observamos que a alegria de criar movimentos inventivos na pesquisa define o que fundamenta as abordagens, métodos, teorias e técnicas nela empregadas. 
O uso da abordagem das metodologias pós-críticas permite também que as lutas acadêmico-científicas façam parte do itinerário proposto para se analisar um problema. Muitas perguntas propõem criar pensamentos outros mais compreensíveis, ou não; assim como, podem ser disparadores de outras discussões num processo de idas e vindas, contornos e curvas, distanciamentos e aproximações.

Afastamo-nos daquilo que é rígido, das essências, das convicções universais, da tarefa de prescrever e de todos os conceitos e pensamentos que não nos ajudam a construir imagens de pensamentos potentes para interrogar e descrever-analisar nosso objeto. Aproximamo-nos daqueles pensamentos que nos movem, colocam em cheque nossas verdades e nos auxiliam a encontrar caminhos para responder nossas indagações (MEYER; PARAÍSO, 2014, p. 18-19).

Com fundamento na menção de estudo acima, o espaço da formação inicial propõe a construção de uma identidade docente, ou ao menos contribui para mobilizar certas concepções de mundo para torna-las mais afetas às questões dos direitos humanos das pessoas. É um assunto que importa para o âmbito da formação, até porque conforme nos aponta Martin Lawn (2001) diferentes vetores atuam na regulação da identidade do/da sujeito-professor. No entanto, esse/a profissional decide o que será feito em sala de aula, mesmo que tantos referenciais preveem a dominação de suas práticas de ensino.

Assim, torna-se imprescindível despolicializar a ação docente, o que permite mobilizar tal possibilidade no contexto da formação inicial de professores/as. Vincular, desse modo, a ação docente às especificidades dos sujeitos aos quais ela está ligada.

A coleta do registro das aprendizagens acerca de assuntos relativos à EDH adquiridas durante o estágio foi realizada por meio de narrativas, reproduzidas nos formulários de avaliação da disciplina, e indicadas por tópicos de análise eleitos essenciais pelas estudantes.

A estratégia de coleta das narrativas se deu de modo prático e de acordo com as experimentações das estudantes do Curso de Pedagogia. As ações tomadas a partir delas foram as seguintes:

a) apresentar a disciplina, ementa, propostas de referências bibliográficas e registro de informações do estágio pertinentes à EDH; 
b) orientar a observação/participação no estágio com base na relevância do papel das estudantes como sujeitos ativos, relacionando teoria e prática, no cotidiano escolar;

c) dar vazão e liberdade, ao fim da disciplina, para as estudantes evocarem fatos entre escolares ou profissionais da educação que representassem formas de assimetrias, ódio e aversão, temas pertinentes à EDH, segundo critérios que considerassem as suas leituras individuais;

d) após o registro das narrativas, cartografar temas que poderiam ser tratados na ação educativa com o enfoque da EDH em ambiente escolar.

É no desenrolar das atividades pertinentes à disciplina, assim, que a construção de diferentes modos de narrar situações do ambiente escolar poderia ser acionada com o intuito de se concretizar um novo conhecimento sobre as práticas de ensino. Isto é, é a partir do material empírico colhido - as experiências das estudantes -, que se poderia encontrar sentido e se problematizar o movimento experiencial como dotado de significado para se alcançar uma prática docente mais compromissada com a realidade dos/das alunos/as das escolas. Em suma, que se poderia aproximar a prática docente e a realidade dos/das discentes em sala de aula.

A narrativa serviu, pois, para compreendermos como as estudantes de Pedagogia nos seus estágios edificaram conhecimentos e experiências que, de um lado, buscam o sentido da ação docente compromissada com a EDH e, de outro, permitem que elas entendam que o cotidiano escolar é impulsor de acontecimentos que podem ser utilizados no contexto escolar, tornando-as produtoras de autonomia.

O objetivo da pesquisa, destarte, foi acolhido pela possibilidade de se problematizar, por meio do cotidiano escolar estagiado, a ação docente e seus compromissos com uma proposta de formação cidadã, ética e política na perspectiva dos direitos humanos. Nesse ponto, surgiu o seguinte questionamento: o plano da disciplina de Educação, democracia e direitos humanos conseguiria propor rupturas com estados de dominação que inferiorizam as diferenças?

Por meio de tal pergunta, as alunas, então, foram levadas a pensar em quais contextos a disciplina poderia contribuir para movimentar processos de produção da verdade sobre as variadas manifestações do preconceito direcionado a públicos específicos durante o estágio curricular obrigatório. 
É mister dizer que partir das experiências das estudantes faz com que as demandas escolares por assuntos específicos da EDH sejam vistas como vinculadas ao real das unidades. Propõe que as estudantes estabeleçam conexões com uma prática de ensino que tenha compromissos ético-políticos mais amplos e em defesa de uma sociedade e de um ambiente escolar nos quais o respeito, a acolhida e a novidade estejam presentes nas relações entre pessoas diferentes. Tais práticas sugerem, portanto, que a ação docente não estabeleça ou reproduza um padrão que regule o corpo das crianças ou as expressões que elas carregam em si.

A disciplina, que levou as estudantes a refletirem em que situações a temática da EDH seria viável, encerrou-se no primeiro semestre de 2019. Durante esse período, episódios que envolviam hostilidade e violência foram narrados e, a partir deles, foi realizado o registro da situação-problema proposta pelas informações coletadas para que a relevância da EDH na formação inicial docente e nas práticas de ensino voltadas à redução de assimetrias, práticas de ódio e aversão às diferenças fosse assegurada.

O presente manuscrito foi estruturado de maneira a apresentar, primeiramente, as propostas da disciplina junto ao Curso de Licenciatura em Pedagogia da IES mencionada; em seguida, a indicar os principais estudos que materializaram tais propostas e, por fim, a oferecer uma reflexão a respeito dos formulários de avaliação da disciplina respondidos pelas estudantes e que destacaram temas que elas consideravam caros à EDH nos contextos escolares nos quais, durante o estágio, presenciaram episódios de preconceito.

\section{PROPOSTA DE ESTUDOS SOBRE EDUCAÇÃO EM DIREITOS HUMANOS (EDH)}

No processo de organização do trabalho didático da disciplina foi criado, a partir da ementa curricular do curso pesquisado, um plano com objetivos, competências, formas de avaliação e referências básicas e complementares. Tal ementa aponta como temas imprescindíveis para a formação docente:

A relação entre educação e direitos humanos na consolidação do Estado Democrático e da Cidadania. Projetos e práticas educativas promotoras da cultura de direitos. Educação e direitos humanos frente às políticas neoliberais. Educação em direitos humanos e formação de professores/as. Educação, conflito e convivência democrática. Metodologias transversalizadas e da transposição didática educação 
em direitos humanos e democracia. Cultura da paz, justiça e equidade social nas práticas escolares. (PROJETO PEDAGÓGICO DE CURSO, 2017, p. 45)

É evidente, pois, que o referencial teórico eleito contribuiu para o atendimento integral à ementa da disciplina. Além disso, a organização didática proposta procurou, por meio de oficinas de pesquisa e diálogos com a teoria, conjugar as dimensões teóricas e práticas para que as estudantes reconhecessem a indissociabilidade desses dois espaços na formação inicial.

O plano da disciplina teve como objetivos: a) compreender conflitos existentes nas disputas sociohistóricas por direitos humanos; b) promover o aprendizado da cultura da paz, justiça e equidade na educação de crianças; c) propor, a partir do conhecimento teórico-prático interdisciplinar, a relação entre direitos humanos e currículo.

Como competências, no plano da disciplina, foram pontuadas: a) o desenvolvimento de capacidades para a mediação de conflitos de interesse entre identidade e diferença; b) a redução dos danos culturais da herança preconceituosa da moralidade conservada nas relações sociais sobre a educação infantil e, por fim, c) a contribuição para a formação da identidade da futura professora compromissada com a EDH.

No que se refere às formas de avaliação, destacam-se os debates, as exposições dialogadas sobre leituras, a prova dissertativa-argumentativa e as pesquisas aplicadas às sujeitos diferentes.

Quanto ao referencial teórico, num primeiro momento, para problematizar os assuntos relativos aos direitos humanos junto às estudantes pesquisadas, e visando alcançar a primeira competência mencionada, elegemos Paulo Carbonari (2008). O autor, em seu texto, traz reflexões a respeito das relações substantivas entre os aspectos históricos dos direitos humanos na perspectiva da democracia, e inicia a discussão destacando a relevância dos movimentos coletivos organizados na luta pela atenção do Estado no cumprimento e ampliação dos direitos sociais em vários setores.

Carbonari, em síntese, acredita que a ideia de dignidade mobiliza a batalha por transformações societárias mais amplas:

Entendemos que democracia é requisito dos direitos humanos e os direitos humanos requisitos da democracia. Ou seja, é impossível pensar a democracia 
senão como forma de satisfação, acolhida e ampliação dos direitos humanos e, por outro lado, os direitos humanos não seriam possíveis em contextos políticos que não oportunizam o exercício das liberdades e dos direitos - democráticos, portanto. A afirmação dos direitos humanos exige sua legitimação como demandas de reconhecimento, portanto, como interação e participação. Por isso, não haveria como propor, advogar, exigir, direitos sem democracia (CARBONARI, 2008, p. 13).

Nota-se, deste modo, que há uma estreita ligação entre democracia e direitos humanos como se, para exercê-los, tivessemos que passar pelo campo da democracia para ter poder de voz e conseguir postular quais demandas nos seriam necessárias para sermos reconhecidos/as como cidadãos/ãs. Esse reconhecimento significa participação, decisão e fruição da liberdade de compor agendas disputadas de poder no interior da conjuntura social em que se vive.

Ora, a discussão sobre dignidade, liberdade e cidadania, nesse cenário de movimentação coletiva, faz parte, segundo Carbonari (2008), do desejo das pessoas de ocuparem espaços para a ampliação de direitos. Com isso, coloca o autor, passamos a evitar que a democracia seja uma pura regra do jogo.

Após a leitura sobre as relações históricas entre essas duas esferas, as estudantes foram apresentadas às diretrizes curriculares para a educação em direitos humanos publicadas pelo Ministério da Educação e Cultura (MEC), em 2012. Nesse documento, a EDH é considerada um eixo do direito à educação e refere-se à adoção de práticas que promovam, protejam e defendam a educação para a transformação social e se apliquem à vida cotidiana e cidadã de crianças e adolescentes a partir dos seguintes princípios:

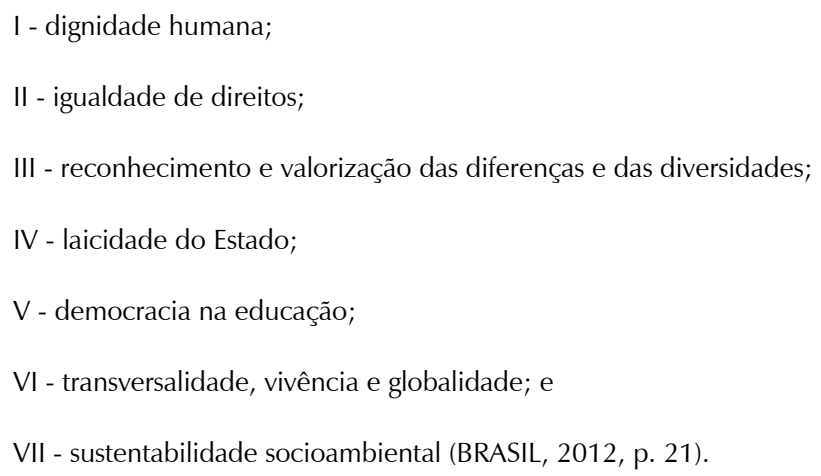


Além de o documento colocar a discussão de forma transversalizada nos currículos das unidades escolares, também cita a necessidade de adequação dos currículos de formação inicial e continuada de professores/as para as novas demandas dos direitos humanos.

Para atender ao Item b posto como objetivo no plano de disciplina acima citado, a saber b) reduzir os danos culturais da herança preconceituosa da moralidade conservada nas relações sociais sobre a educação de crianças pequenas, discutimos sobre a interculturalidade como uma proposta para a formação e prática docente em EDH (CANDAU; SACAVINO, 2013), sobre a educação para a democracia (EPD) (BENEVIDES, 2004) e sobre a educação em direitos humanos (BENEVIDES, 2001).

A fim de que pudéssemos levantar situações que poderiam ser encaradas como desafio na formação de professores/as compromissados com a EDH, compreendida, assim, como assunto necessário à docência, trabalhamos, também, com as autoras já mencionadas, Vera Candau e Suzana Sacavino (2013). As pesquisadoras apontam sete desafios possíveis de serem encontrados em programas formativos que se associam à EDH. São eles:

1. Desconstruir a visão do senso comum sobre direitos humanos;

2. Assumir uma concepção de educação em direitos humanos e explicar o que se pretende atingir em cada situação concreta;

3. Articular ações de sensibilização e formação;

4. Construir ambientes educativos que respeitem e promovam os direitos humanos;

5. Incorporar a educação em direitos humanos no currículo escolar;

6. Introduzir a educação em direitos humanos na formação inicial e continuada de professores/as;

7. Estimular a produção de materiais de apoio (CANDAU; SACAVINO, 2013, p. 65-66)

Diante de tais desafios, Candau e Sacavino concluem que atuar na formação docente com o enfoque na EDH é complexo, uma vez que esse processo visa romper com o conservadorismo e legitimar o reconhecimento da diferença; faz o/a educador/a assumir uma postura que informa seus/suas 
alunos/as sobre os seus direitos, para que eles(as) criem em si uma cultura de participação que, em muitos casos, pode se tornar resistência em locais que concentram poder.

As autoras (CANDAU; SACAVINO, 2013) lembram, ainda, que desenvolver ações pontuais no decurso da formação não é suficiente para romper com o pensamento preconceituoso de professores/as que acreditam que a temática não é relevante para o currículo. É preciso se valer de estratégias pedagógicas ativas e participativas que permitam que os/as professores/as, em uma primeira instância, se eduquem em direitos humanos, para que, na sequência, saibam conduzir processos educativos que articulem a afetividade, a cognição e a dimensão sociopolítica da docência.

Abordada a formação docente em direitos humanos, propusemos às estudantes uma leitura sobre EPD e EDH a partir dos conceitos apresentados por Maria Victória Benevides $(2001 ; 2004)$.

Os estudos da autora sobre a EPD confirmam que o tema se relaciona diretamente à experimentação dos direitos de cidadania na sociedade e as formas de ampliar a atividade política. Benevides (2004) mostra que a EPD comporta duas dimensões: a formação para os valores republicanos e democráticos e a formação para a tomada de decisões políticas em todos os níveis.

Na concepção da pesquisadora, os valores republicanos referem-se: a) ao respeito às leis; b) ao respeito ao bem público e, c) ao sentido de responsabilidade no exercício do poder; já os valores democráticos, referem-se a) à virtude do amor à igualdade, b) ao respeito integral aos direitos humanos e c) ao acatamento da vontade da maioria, legitimamente formada. Benevides, assim, atesta que a educação para a democracia é um processo contínuo e de longa duração.

Em relação ao assunto de que trata a $\mathrm{EDH}$, a autora diz que:

A Educação em Direitos Humanos parte de três pontos essenciais: primeiro, é uma educação de natureza permanente, continuada e global. Segundo, é uma educação necessariamente voltada para a mudança, e terceiro, é uma inculcação de valores, para atingir corações e mentes e não apenas instrução, meramente transmissora de conhecimentos. Acrescente-se, ainda, e não menos importante, que ou esta educação é compartilhada por aqueles que estão envolvidos no processo educacional - os educadores e os educandos - ou ela não será educação e muito menos educação em direitos humanos (BENEVIDES, 2001, p. 08). 
Associar a ação pedagógica às orientações previstas para EDH visa, pois, promover uma cultura do respeito à dignidade humana, da liberdade enquanto valor ético-político central nas relações sociais e da justiça e da solidariedade como forma de eliminar preconceitos que não toleram as diferenças. Rompe com tradições preconceituosas historicamente definidas e leva a pensar que os direitos humanos são para todos/as, independentes de qualquer norma que padronize acessos e privilégios.

Vera Candau (2008), nesse contexto, entende a relação entre direitos humanos, educação e interculturalidade como fundamental para se problematizar igualdade e diferença. A autora, em sua obra, pontua os principais desafios enfrentados na promoção de uma educação intercultural cujas abordagens perfazeriam um itinerário crítico e emancipador.

Candau (2008) identifica quatro núcleos essenciais como desafios para a educação intercultural. O primeiro é a desconstrução, que tem por objetivo penetrar o imaginário social onde se naturalizam os preconceitos e romper a rede de estereótipos etnocêntricos e monoculturais que estão presentes nos currículos escolares.

O segundo núcleo proposto pela autora refere-se à articulação entre igualdade e diferença no quadro das políticas educativas: "Essa preocupação supõe o reconhecimento e a valorização das diferenças culturais, dos diversos saberes e práticas e a afirmação de sua relação com o direito à educação de todos/as" (CANDAU, 2008, p. 53). No terceiro núcleo, Candau caracteriza o resgate dos processos de constituição cultural nos níveis pessoais e coletivos.

Por fim, o último núcleo mostra a importância de se oportunizar interações com a diferença, com outras pessoas, com diferentes modos de viver e de se expressar. Somente a partir da percepção desses núcleos será possível promover a emancipação de sujeitos que foram historicamente desprivilegiados na sociedade. Eles são, destarte, indispensáveis para correção de marcas discriminatórias de minorias sociais:

Visam melhores condições de vida para os grupos marginalizados, a superação do racismo, da discriminação de gênero, da discriminação étnica e cultural, assim como das desigualdades sociais. Outro aspecto fundamental é a formação para uma cidadania aberta e interativa, capaz de reconhecer as assimetrias de poder entre os diferentes grupos culturais e de trabalhar os conflitos e promover relações solidárias (CANDAU, 2008, p. 54) 
Em resumo, a educação intercultural contribui para uma proposta de direitos humanos apoiada no reconhecimento da vida de cada pessoa e da diferença, em diálogo com as demandas diversas de outros grupos sociais.

Nessa mesma perspectiva, Daniela Auad (2002) aproxima a educação para a democracia à coeducação e relações de gênero. Parte, também, das categorias analíticas de Benevides (2002) para articular o gênero e a educação em direitos humanos.

A autora entende que tanto o programa de educação em direitos humanos, quanto a educação para a democracia devem se unir à igualdade de gênero, por mais que esta ainda não seja uma realidade em nosso país.

De acordo com Auad (2002), a escola não está pronta para problematizar, em seu espaço, as relações entre os gêneros masculino e feminino. Tanto a educação para a democracia, como a coeducação precisam fazer parte da ação pedagógica de professores/as para que eles/as possam concretizar práticas não sexistas.

Perceber gênero como categoria empírica seria o modo de não tornar invisível o gênero nas diferentes esferas da sociedade, como nas políticas públicas de educação e de direitos humanos; seria perguntar como ele é experimentado e estruturado em determinada cultura (AUAD, 2002, p. 2003)

A condição das masculinidades e feminilidades, portanto, é um assunto necessário na educação de crianças e adolescentes para que eles/as possam experimentar expressões de gênero menos tolhidas e mais flexíveis e se tornar cidadãos mais abertos à novidade. Sobre o gênero, pode-se dizer que as pessoas, por acreditarem que a construção de sua subjetividade precisa estar alinhada aos padrões definidos pela distinção biológica, não se expressam como são em certos espaços, e a escola é apenas um deles.

Neste ponto da análise, chegamos ao Item c do plano da disciplina, o qual se refere à formação da identidade da futura professora comprometida com a EDH. Candau e Sacavino (2013), recordemos, apontam como terceiro e sexto desafios à EDH na formação de professores: 3. Articular ações de sensibilização e formação; 6 . Introduzir a educação em direitos humanos na formação inicial e continuada de professores/as, realizou-se contato com diferentes aspectos metodológicos para se efetivar tal proposta de EDH tranversalizada ao currículo. 
Eduardo Bittar (2008), epistemologicamente baseado na perspectiva freireana, oferece argumentos que podem nos auxiliar metodologicamente nesse assunto. $\mathrm{O}$ autor acredita que a EDH está vinculada à direção sociopolítica que orienta a educação no tempo presente. Se compromissada com a ampliação da cidadania, da autonomia, da emancipação e da liberdade, a educação precisa preparar o/a estudante não apenas para problematizar em um nível abstrato, mas conscientizá-lo sobre o “[...] passado histórico, tornando-o presente, para análise da responsabilidade individual ante os destinos coletivos futuros" (BITTAR, 2008, p. 317).

Bittar acrescenta que é no contexto atual, numa sociedade de controle, que a ação pedagógica precisa estar comprometida com a construção de uma subjetividade crítica que fortaleça a autonomia das pessoas, tornando-as capazes de resistir a todas as amarras.

A descolorida apatia política, a invisibilidade dos problemas sociais, a indiferen-
ça social, a insatisfação sublimada no consumo, a inércia mobilizadora precisam
ser superadas através de um movimento pedagógico que aja na contramão deste
processo (BITTAR, 2008, p. 320).

Para o autor, uma educação politizada só consegue libertar pessoas presas a padrões socioculturais historicamente definidos quando estimula a participação, o diálogo e a formação da consciência crítica. Coloca como sugestão, então, a partir dos estudos de Habermas, uma pedagogia da ação comunicativa.

A proposta dessa pedagogia, explica Bittar (2008), é lidar com uma prática educativa que se opõe à autoridade e adota o princípio da liberdade como requisito fundamental para a criação de uma cultura do exercício democrático de convívio social.

O autor, deste modo, propõe como aspecto metodológico da EDH uma ação docente que consiga motivar as pessoas a realizarem práticas democráticas, a pensarem de modo autônomo acerca das desigualdades, a analisarem suas atitudes e mudá-las, e a se sensibilizarem diante da responsabilidade ética com o outro.

\section{DISCURSOS DAS ESTUDANTES SOBRE OS TEMAS NECESSÁRIOS À EDH}

Por meio das discussões teóricas, as estudantes puderam se relacionar com o tema e refletir sobre os aspectos inerentes à EDH e que carecem à 
ação docente no ambiente escolar. Elas tiveram a oportunidade de participar das relações consolidadas nas unidades onde cumpriram o estágio curricular obrigatório, observando, através dessa experiência, uma série de problemas que, a longo prazo, prejudicam a formação da identidade social do cidadão.

Esses espaços trouxeram à luz cenas de intolerância, preconceito e incitação do ódio às diferenças, cenas que proporcionaram às estudantes percepções reais de temas caros à EDH.

No encerramento da disciplina, no primeiro semestre de 2019, as estudantes, como atividade final, tiveram que registrar tais percepções no instrumental de avaliação do curso. Tiveram que decidir, a partir do evento que julgaram mais nocivo à infância, o assunto a ser trabalhado via EDH junto às práticas docentes. Em suma, eis os tópicos que trouxeram:

- Tolerância às diferenças de classe social;

- Formação política para entender relações entre o individual e coletivo;

- Bullying;

- Respeito às pessoas autistas;

- Exclusão de crianças com deficiências;

- Como ser ético com alguém que pensa e é diferente de mim;

- Solidariedade humana (ESTUDANTES, 2019).

Esses assuntos podem ser tratados tanto na dinâmica da formação pessoal, quanto como questões de formação social que estão presentes no cotidiano das crianças e que coexistem com construções sociais previamente definidas (antes mesmo de elas se tornarem protagonistas do próprio poder de decisão). Eles trazem para a prática educativa uma multiplicidade de entraves, necessidades e demandas por uma educação libertária que consiga educar para a cidadania, ética, sociabilidade etc.

No momento em que evocaram tais situações, as estudantes apresentaram memórias significativas para a formação da identidade de um/a docente comprometido/a com a acolhida da diferença proposta pelo plano da disciplina. Histórias preocupantes que justificavam o porquê da escolha pelo tema acima assinalado. As futuras professoras, assim, puderam pensar em circuns- 
tâncias no contexto do ensino da EDH que amenizassem o problema e em ações pró-ativas que evitassem adultos graduados numa educação egoística, intolerante e disseminadora do ódio.

A disciplina Educação, democracia e direitos humanos faz parte de um novo projeto pedagógico-curricular do Curso de Pedagogia da IES pesquisada. É importante, pois, destacar a novidade de sua proposta, sobretudo num momento político em que a crítica aos direitos humanos por parte do novo Presidente da República é intensa. É o que assinala, por exemplo, Erasto Mendonça (2018).

O atual Presidente, bem o recorda o autor, pautou a sua campanha em discursos surrados tais quais "bandido bom é bandido morto", "direitos humanos são só para humanos bandidos" (grifo do autor). Isso sem mencionar as inúmeras e exageradas referências depreciativas a negros, mulheres e, principalmente, a gays, lésbicas, bissexuais e trans (LGBT).

Os direitos humanos, na concepção do Presidente, devem ser associados apenas à questão da segurança pública:

O redirecionamento das políticas de Direitos Humanos é anunciado, priorizando a defesa das vítimas da violência, tema inscrito ao lado da reformulação do Estatuto do Desarmamento, da redução da maioridade penal, da garantia aos policiais do 'excludente de ilicitude' 10 , da criminalização de movimentos sociais de ocupação, dentre outras medidas absolutamente em confronto com a concepção contemporânea de Direitos Humanos. (MENDONÇA, 2018, p. 477)

Observa-se, pois, a urgência de se abordar temas relacionados aos direitos humanos já nas séries iniciais do Ensino Fundamental. A EDH será, deste modo, um instrumento de enfrentamento e estranhamento. Enfrentamento porque a ideia é oportunizar a transversalidade do assunto no currículo escolar e a construção de saberes subversivos às regras e padrões sociais, que acoIham a diferença, a coletividade e a liberdade como um valor ético-político. Estranhamento porque visa colocar o novo como sujeito existente, que não mina a existência do Eu nem a do Outro.

Produzir tais deslocamentos é, destarte, fundamental para que não caiamos na ideia propagada pelo novo governo de que a maior parte dos avanços produzidos em matéria de direitos humanos está vinculada à pura e mera ideologia (MENDONÇA, 2018). 
Algumas pesquisas, como a de Elisa Mainardi (2014), apresentam os desafios para se concluir um trabalho educativo com essa temática. A autora analisa o registro das reuniões de elaboração do projeto político-pedagógico de um grupo de professores/as de escolas do norte do Rio Grande do Sul (RS). Observa, nesse material, concepções e práticas que violam os direitos humanos dos/das alunos/as e aponta, ao fim, situações que são potenciais ferramentas para o enfrentamento do problema.

Diante dos relatos colhidos, e identificados os desafios, Mainardi (2014) cria quatro categorias de análise: 1 - representações acerca do eu e do outro; 2 - representação acerca da família; 3 - representações sobre a prática dialógica na escola; 4 - representações acerca do ECA.

Segundo a autora, existe uma série de negações, silenciamentos e apagamentos que representam a dificuldade dos/das professores/as e da equipe de profissionais da educação em serem mais flexíveis diante da novidade de sujeitos que estão ingressando no ambiente escolar:

No contexto da escola, percebe $\square$ se através das manifestações acerca das inquietações pedagógicas, da leitura de contexto escolar e das exigências entendidas como necessárias na efetivação de uma educação de qualidade, que do ponto de vista dos desafios, um dos problemas a ser enfrentado diz respeito ao desvelamento e superação das concepções preconceituosas enraizadas num pensamento pedagógico ainda conservador, discriminador, excludente (MAINARDI, 2014, p. 15).

Como Mainardi (2014) aponta em sua pesquisa, a ação docente é orientada por práticas que conservam tradições. Isso pode ser um problema, já que invisibiliza discussões no terreno dos direitos humanos, os quais são então qualificados como sem sentido, como gasto desnecessário de recurso público com situações/sujeitos que não contribuem para o desenvolvimento da sociedade.

A ideia de educação em direitos humanos apresentada pelas estudantes, ao contrário, relaciona-se à convivência ética, justa e humana, num desejo por uma cultura de paz. A compreensão dos direitos humanos, portanto, envolve a universalidade do acesso, o que nos leva a pensar nas diferenças e nas estratégias de enfrentamento, por meio da educação, para protegê-las.

Provocar nos/as alunos/as atitudes que os/as façam reivindicar a ampliação dos direitos humanos é um potencial da EDH. Com essa afirmação, Eni 
Orlandi (2007) analisa dois enunciados contidos na formação discursiva, a saber: 1. Todos são iguais perante a lei; 2 . Todos têm direitos à diferença. Na concepção da autora, eles trazem sentidos e posições de sujeitos diferentes. Isso significa que a ideologia opera no controle dos sentidos.

Ao estudar os fundamentos teóricos e metodológicos da EDH, Orlandi reconhece que é preciso escutar e instaurar outras práticas de ensino que atravessem o discurso dominante:

Se assim é, é preciso que os diferentes discursos, muitas vezes silenciados pelo alarido do processo dominante de produção de sentidos no capitalismo, possam ser ouvidos e investidos na realidade histórica e social contemporânea, de tal modo que essas outras experiências encontrem voz e possam (re) significar(se) no coro dos Direitos Humanos, em nossos dias, tão surdos e emudecidos, não porque não se fala neles, mas porque eles já não fazem sentido (ORLANDI, 2007, p. 310).

Para a pesquisadora, os professores/as que trabalham com a EDH devem fazer com que seus/suas alunos/as reflitam sobre o compromisso social do sentido do "não possível" para o sentido "possível". Devem promover experiências cotidianas nas quais o respeito, a dignidade e uma boa convivência façam parte da constituição da identidade social dos/das discentes.

\section{CONSIDERAÇÕES DE UMA PRÁTICA IM/POSSÍVEL}

Este projeto, enfim, inserido no contexto da disciplina Educação, democracia e direitos humanos, teve por objetivo articular as percepções e experiências formativas de estudantes do curso de Licenciatura em Pedagogia de uma IES do leste sul-mato-grossense durante os seus estágios obrigatórios nas séries iniciais do Ensino Fundamental e propor uma ruptura com preconceitos histórica e culturalmente definidos por programas societários dominantes.

A recuperação das experiências cotidianas das estudantes - futuras professoras - trouxe à tona questões contemporâneas que poderiam resultar em significados totalizantes e unívocos, como a ideia de sujeito, diferença, identidade, e que permitiriam que a diversidade, o multiculturalismo e a multiplicidade fizessem da docência uma ação comprometida ética e politicamente com os direitos humanos. 
A ideia foi possibilitar que a convivência democrática e ética estivesse presente no ambiente escolar. Como produto discursivo, os enunciados existentes no contexto social poderiam, então, se manifestar por meio de uma prática de ensino problematizadora.

Conforme as experiências foram sendo narradas, vimos que os assuntos eleitos como necessários pelas estudantes se localizavam no terreno da convivência ética, onde o respeito e a vontade de cultura da paz tivessem sentido e não fossem tratados como um tema de defesa da marginalidade. Isso só seria possível se a EDH fosse conteúdo presente nas práticas educativas profissionalizadas e, sobretudo, direcionadas ao público.

É relevante mencionar que tais assuntos perdem sentido na prática docente se ela se vê descontextualizada de discussões referentes aos direitos humanos ou afastada das requisições de grupos socialmente inferiorizados. Observa-se, com isso, que para que tais discussões sejam possíveis no ambiente escolar, a docência precisa, em muitos casos, ser engajada.

O trabalho teórico-prático realizado com as estudantes, em síntese, mostra a necessidade de um permanente exercício por parte do/da professor/a de Ensino Superior e também dos alunos em formação inicial na escolha de metodologias e práticas de ensino que se relacionem ao campo dos direitos humanos. Exige, assim, de ambos/as, professores/as e futuros/as professores/ as, que refaçam caminhos já traçados, repensem estratégias, reelaborem procedimentos e flexibilizem sua visão de mundo, atentando-se para a provisoriedade, a multiplicidade e a fluidez de sentidos sobre o existir.

Resumo: Por meio de um formulário de coleta de narrativas, um grupo de sete alunas de um Curso de Licenciatura em Pedagogia de uma instituição de ensino superior (IES) privada do Mato Grosso do Sul trouxe à tona assuntos acerca da educação em direitos humanos (EDH) que poderiam ser tratados em suas práticas como professoras. O objetivo deste trabalho, pois, foi de refletir sobre como a EDH poderia movimentar processos estruturais de construção da diferença na formação do sujeito cidadã/ao em ambiente escolar, uma vez que as alunas, em experiências de estágio curricular do curso, observaram que temas complexos da realidade social são quase sempre silenciados em sala de aula com crianças pequenas. $\mathrm{O}$ assunto foi abordado com o apoio dos estudos pós-críticos em educação, especialmente das perspectivas pós-estruturalistas, e se valeu de um formulário de avaliação da disciplina com foco na narrativa, no qual as estudantes registraram suas concepções de temas que consideravam necessários à EDH. Por fim, as práticas de ensino interessadas em EDH permitirão que futuros/as professores/as refaçam caminhos já traçados, readequem estratégias, reelaborem procedimentos e flexibilizem a sua visão de mundo, atentando-se à provisoriedade, à multiplicidade e à fluidez de sentidos sobre o existir.

Palavras-chave: Educação em direitos. Formação inicial docente. Liberdade. 


\begin{abstract}
From a collection of ethnographic narratives forms, a group of seven students from a Pedagogy Degree Course of a private higher education institution (HEI) in the State of Mato Grosso do Sul brought some issues about Human Rights Education (HRE) that they could approach in their practice as teachers. The objective of this work was to reflect on how the HRE could move structural processes of construction of the differences in the school environment and in the formation of the citizen, since the students during their internship experiences observed that complex themes of social reality are silenced in the classroom with young children. The subject was approached through post-critical studies in education, especially from the perspective of poststructuralism and the use of a subject evaluation form, where students recorded their conceptions of topics they considered necessary for HRE. Finally, the teaching practices interested in HRE will enable future teachers to redo paths already laid out, readjust strategies, re-elaborate procedures and make their world view more flexible, paying attention to provisionality, multiplicity and fluidity of senses about existing.
\end{abstract}

Keywords: Human rights education. Initial teacher training. Freedom.

Resumen: A través de un formulario de recopilación narrativa, un grupo de siete estudiantes de un Curso de Pedagogía en una institución privada de educación superior (HEl) en Mato Grosso do Sul planteó cuestiones sobre la educación en derechos humanos $(\mathrm{EDH})$ que podrían ser tratados en sus prácticas como docentes. El objetivo de este trabajo, por lo tanto, fue reflexionar sobre cómo el EDH podría mover los procesos estructurales de construcción de la diferencia en la formación del sujeto ciudadano en el ambiente escolar, ya que los estudiantes, en experiencias de pasantía curricular del curso, observaron que los temas Los complejos de realidad social casi siempre se silencian en el aula con niños pequeños. El tema se abordó con el apoyo de estudios pos críticos en educación, especialmente desde las perspectivas postestructuralistas, y utilizó una forma de evaluación de la disciplina centrada en la narrativa, en la que los estudiantes registraron sus concepciones de temas que consideraban necesarios para el EDH Finalmente, las prácticas de enseñanza interesadas en EDH permitirán a los futuros maestros rehacer caminos ya descritos, reajustar estrategias, rediseñar procedimientos y hacer que su visión del mundo sea más flexible, prestando atención a la provisionalidad, multiplicidad y fluidez de los significados sobre a existir.

Palabras clave: educación en derechos. Formación inicial del profesorado. Libertad.

\title{
REFERÊNCIAS
}

ALVES, Gilberto Luis. Organização do trabalho didático: a questão conceitual. Acta Scientiarum, Maringá, v. 34, p. 169-178, 2012. Disponível em: http://eduem.uem.br/ojs/index.php/ActaSciEduc/article/viewFile/17180/9978. Acesso em: 12 ago. 2018.

ANDRÉ, Marli. Formação de professores: a constituição de um campo de estudos. Educação, Porto Alegre, v. 33, n. 3, p. 174-181, set./dez. 2010.

BAUMAN, Zygmunt; LYON, David. Vigilância Líquida. Rio de Janeiro: Zahar, 2013.

BENEVIDES, Maria Victoria. Educação em direitos humanos: de que se trata? Convenit Internacional (USP), São Paulo, v. 6, p. 43-50, 2001. Disponível em: http://portal.mec.gov.br/seb/ arquivos/pdf/Etica/9_benevides.pdf. Acesso em: 12 mar. 2019.

BENEVIDES, Maria Victoria. Educação para a democracia. Lua Nova: Revista de Cultura e Política, São Paulo, n. 38, p. 223-237, 2004. Disponível em: http://www.scielo.br/scielo.php?script=sci_ arttext\&pid=S0102-64451996000200011. Acesso em: 12 mar. 2019.

BITTAR, Eduardo C. B. Educação e metodologia para os direitos humanos: cultura democrática, autonomia e ensino jurídico. In: DIAS, Adelaide A. et al. (Org.). Educação em Direitos Humanos: Fundamentos Teórico-Metodológicos. João Pessoa: Editora Universitária, 2007. p. 313-334.

BRASIL. Parecer CNE/CP n 8 de 2012. Diretrizes Nacionais para Educação em Direitos Humanos. Brasília. Disponível em: https://www.mdh.gov.br/navegue-por-temas/educacao-em-direitos-humanos/DiretrizesNacionaisEDH.pdf. Acesso em: 14 ago. 2019. 
CANDAU, Vera Maria Ferrão. Direitos humanos, educação e interculturalidade: as tensões entre igualdade e diferença. Revista Brasileira de Educação, Campinas, v. 13, n. 37, jan./abr. 2008. Disponível em: http://www.scielo.br/pdf/rbedu/v13n37/05.pdf. Acesso em: 14 ago. 2019.

CANDAU, Vera Maria Ferrão; SACAVINO, Suzana B. Educação em direitos humanos e formação de educadores. Educação, Porto Alegre, v. 36, n. 1, p. 59-66, jan./abr. 2013.

CARBONARI, Paulo C. Democracia e direitos humanos: reflexões sobre a agenda substantiva e abusada. In: BITTAR, Eduardo C. B; TOSI; Giuseppe (Org.) Democracia e Educação em Direitos Humanos numa Época de Insegurança. Brasília: SEDH, 2008. p. 13-34.

LAWN, Martin. Os professores e a fabricação de identidades. Currículo sem Fronteiras, v. 1, n. 2, p. 117-130, jul./dez. 2001. Disponível em: http://www.curriculosemfronteiras.org/vol1 iss2articles/lawn.pdf. Acesso em: 12 jan. 2020.

MAINARDI, Elisa. Educação em direitos humanos: desafios, resistências e possibilidades de desenvolvimento de uma cultura de humanização na escola. In: ANPED Sul, 2014, Florianópolis. X ANPED Sul. Florianópolis: Editora UDESC, 2014. p. 1-17. Disponível em: http://xanpedsul.faed. udesc.br/arq_pdf/719-0.pdf. Acesso em: 12 ago. 2019.

MAINARDES, Jeferson; CARVALHO, Isabel C. M. de. Autodeclaração de princípios e de procedimentos éticos na pesquisa em Educação. In: ASSOCIAÇÃO NACIONAL DE PÓS-GRADUAÇÃO E PESQUISA EM EDUCAÇÃO. Ética e pesquisa em educação: subsídios. v. 1. Rio de Janeiro, 2019. Disponível em: http://www.anped.org.br/sites/default/files/images/etica_e_pesquisa_em_ educacao_-_isbn_final.pdf. Acesso em: 10 out. 2019.

MENDONÇA, Erasto F. Desafios à educação em direitos humanos no Brasil após a Constituição de 1988. Revista Retratos da Escola, Brasília, v. 12, n. 24, p. 465-479, nov./dez. 2018. Disponível em: http://retratosdaescola.emnuvens.com.br/rde/article/viewFile/905/pdf. Acesso em: 16 ago. 2019.

MEYER, Dagmar Estermann; PARAISO, Marlucy Alves. Metodologias de pesquisas pós-críticas ou sobre como fazemos nossas investigações. In: . Metodologias de pesquisas pós-críticas em educação. 2. ed. Belo Horizonte: Mazza Edições, 2014. p. 17-24.

ORLANDI, Eni Puccinelli. Educação em direitos humanos: um discurso. In: SILVEIRA, Rosa Maria G. et al. (Org.). Educação em direitos humanos: fundamentos teórico-metodológicos. João Pessoa: Editora Universitária, 2008, p. 295-311.

PROJETO PEDAGÓGICO DE CURSO. Curso de Pedagogia. Faculdades Integradas de Três Lagoas/ MS, Três Lagoas, 2017.

Recebido em Novembro de 2020

Aprovado em Fevereiro de 2021 